\title{
Forestry in Action
}

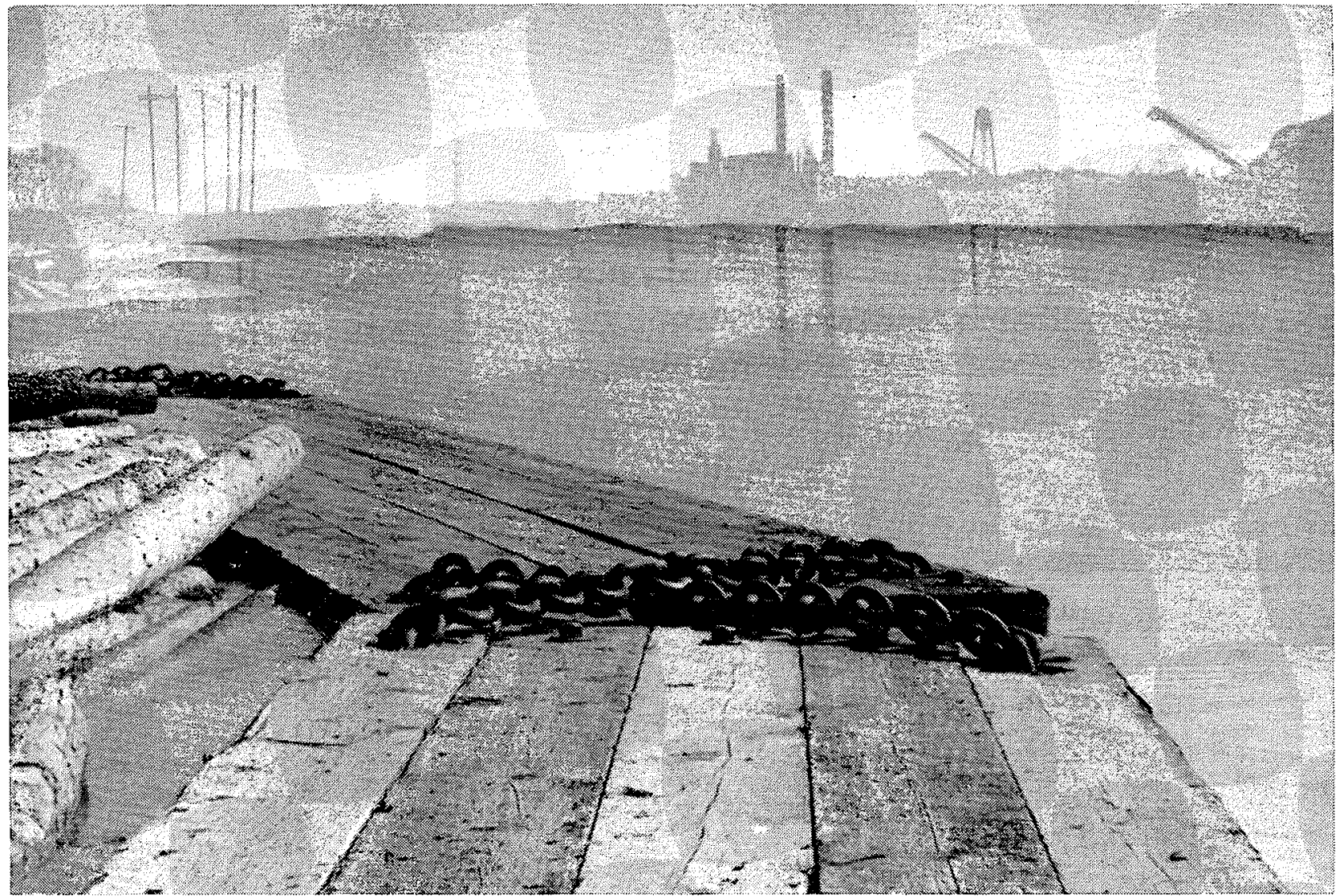

Pressure treatment with creosote preservatives prolongs the life of boom timbers. Initially the timbers float an

inch or two lower but after a few years they float higher than their untreated equivalent.

\section{Preservative Treated Boom Timbers Last Longer}

The Kapuskasing mill of the Spruce Falls Paper Co., has used Douglas fir holding booms since 1930. A decision to specify pressure creosote treatment was made in 1951 because logs became increasingly waterlogged; deep checks developed in the timbers and decay was hastened by dirt and seeds which settled in the wood.

Their standards for boom timbers are: $14^{\prime \prime} \mathrm{x}$ $14^{\prime \prime} \times 40 \mathrm{ft}$. long, Coast Douglas Fir, rough, incised and pressure treated to a net retention of $8 \mathrm{lbs}$. creosote per cubic foot of wood. To reduce costs, foresters also specify the use of anchor staples (they resist chain abrasion) and that logs be framed before treatment.

Creosote preserves timber and retards water logging. Research has provided the $\mathrm{Ka}$ puskasing mill with boom timbers designed for endurance in demanding conditions contributed by W. J. Whelton, Wood Preserving Division, Domtar Chemicals Limited, Downsview, Ontario, following presentation to the Canadian Institute of Timber Construction, Ottawa.

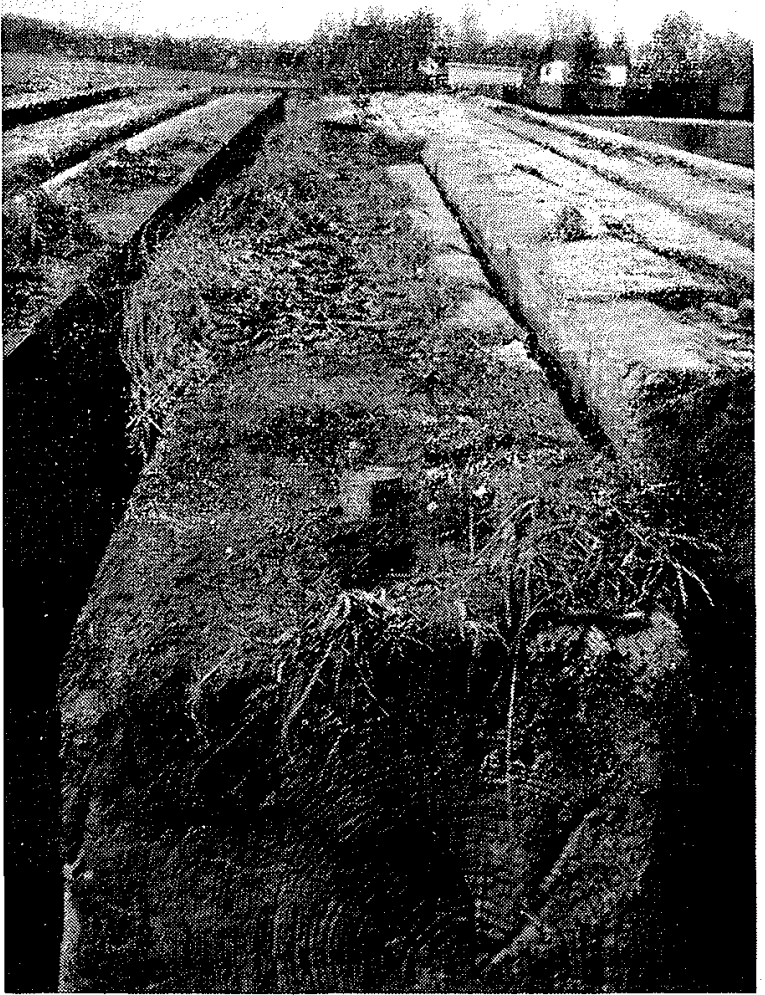

Plants commonly grow on old, untreated boom timbers. Once this happens rapid decay follows, and substantially shortens the life of the boom timbers. 